\title{
Increase in Blood Pressure in Pheochromocytoma Induced by Domperidone and Metoclopramide
}

\author{
Shuichi Ichikawa, Zenpei Ono, Masashi Arai and \\ Kazuhiko Murata \\ The Second Department of Internal Medicine, Gunma \\ Universdty School of Medicine, Maebashi 371
}

\begin{abstract}
Ichikawa, S., Ono, Z., AraI, M., and Murata, K. Increase in Blood Pressure in Pheochromocytoma Induced by Domperidone and Metoclopramide. Tohoku J. exp. Med., 1985, 146 (2), 149-152 — Administration of two dopamie antagonists, domperidone and metoclopramide, gave a marked rise in blood pressure with an increase in plasma catecholamines in two patients with pheochromocytoma. The result suggests that not only metoclopramide but also domperidone might induce hypertensive crisis in pheochromocytoma._- dopamine antagonist; catecholamines; hypertensive crisis; hypertension
\end{abstract}

It has been reported that hypertensive crisis occurs durimg the treatment with the dopamine antagonist, metoclopramide (MCP) or sulpiride, in patients with pheochromocytoma (Plouin et al. 1976; Agabiti-Rosei et al. 1977). Although precise mechanisms for the crisis have not been elucidated, Oishi et al.(1983) reported that MCP and sulpiride released catecholamines directly from an adrenal tumor in in vitro experiments.

Both MCP and sulpiride are benzamide derivatives, whereas domperidone (DPD) belongs to butyrophenones and does not enter into the central nervous system (Agid et al. 1979).

The present study was aimed to determine whether DPD, like MCP, induces a rise of blood pressure in 2 patients with pheochromocytoma confirmed later by operation.

The first patient, a 64-year-old man with intermittent hypertension, received intravenously $5 \mathrm{mg}$ of metoclopramide (MCP) at hypertensive and $10 \mathrm{mg}$ of MCP at non-hypertensive stage. At hypertensive stage, $10 \mathrm{mg}$ of domperidone (DPD) was also injected. Blood pressure and heart rate were continuously recorded by an automatic sphygmomanometer, and plasma catecholamines were measured

Received July 25,1984; accepted for publication, January 24, 1985. 
before the injection and afterwards serially by use of high-performance liquid chromatography with an electrochemical detector.

Blood pressure began to increase $2 \mathrm{~min}$ after the injection of MCP, $5 \mathrm{mg}$, from $150 / 94 \mathrm{mmHg}$ to $182 / 111 \mathrm{mmHg}$ and reached a peak at $53 \mathrm{~min}(225 / 117 \mathrm{mmHg})$. Both plasma noradrenaline (NA) and adrenaline (Adr) increased as blood pressure rose. There was a slight increase in blood pressure by MCP, $10 \mathrm{mg}$, from 105/72 $\mathrm{mmHg}$ to $142 / 82 \mathrm{mmHg}$ at a peak after $30 \mathrm{~min}$ (Fig 1). DPD, $10 \mathrm{mg}$, also raised blood pressure drastically at $2 \mathrm{~min}$ after the injection from $151 / 94 \mathrm{mmHg}$ to $197 /$ $110 \mathrm{mmHg}$ and reached a peak at $60 \mathrm{~min}(250 / 140 \mathrm{mmHg})$. Plasma catecholamines were also increased markedly as blood pressure rose (Fig. 2). Two weeks after the removal of right adrenal tumor, paroxysmal hypertension disappeared and the test with $10 \mathrm{mg}$ of MCP and DPD were again carried out. No changes in blood pressure or plasma catecholamines were observed.

The second patient, 27-year-old woman with persistent hypertension received intravenously $10 \mathrm{mg}$ of MCP and $10 \mathrm{mg}$ of DPD. Both agents induced a marked
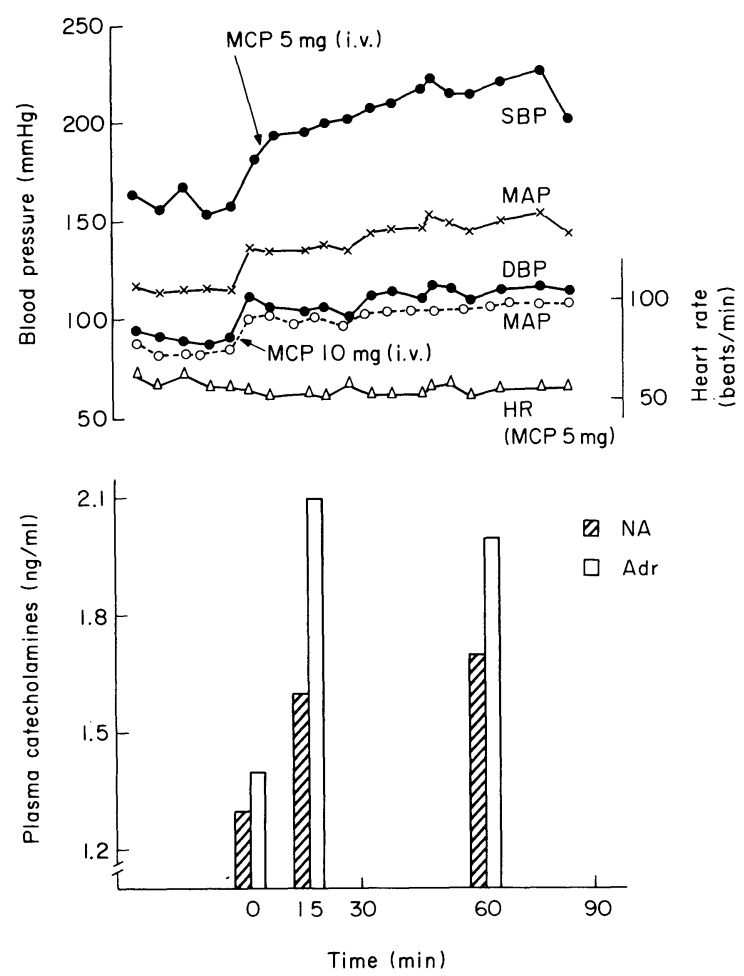

Fig. 1. Effect of metoclopramide (MCP) $5 \mathrm{mg}$ or $10 \mathrm{mg}$ on blood pressure, heart rate, and circulating noradrenaline (NA) and adrenaline (Adr) in the first patient. SBP, systolic blood pressure; DBP, diastolic blood pressure; MAP, mean arterial pressure; HR, heart rate. 


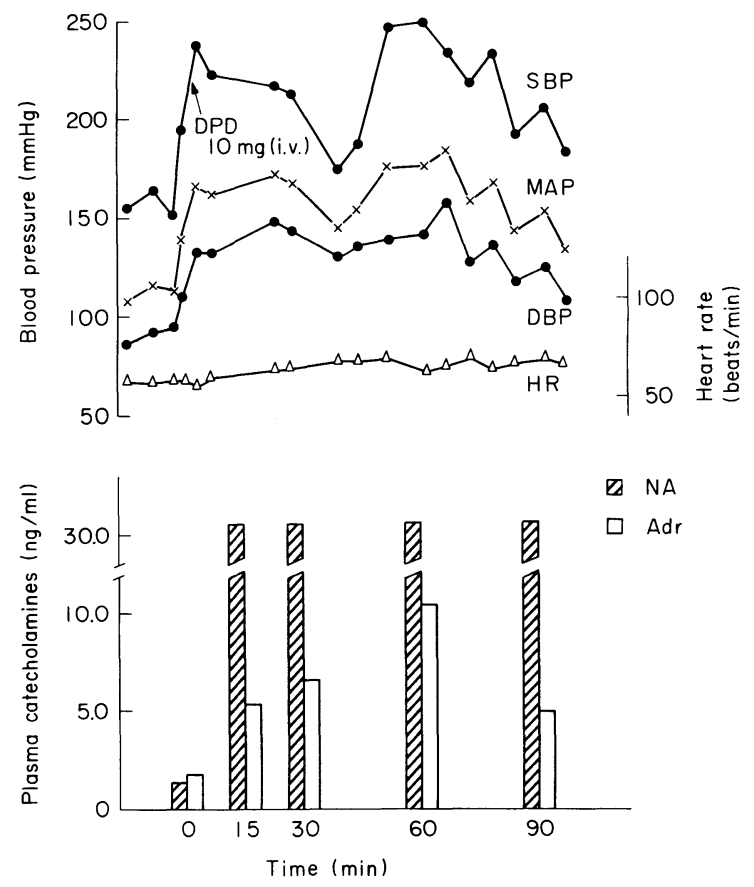

Fig. 2. Effect of domperidone (DPD) $10 \mathrm{mg}$ on blood pressure, heart rate, circulating noradrenaline (NA) and adrenaline (Adr) in the first patient. Abbreviations are the same as in Fig. 1

increase in blood pressure and nausea, which made us use phentolamine at $30 \mathrm{~min}$ after the treatment. The MCP administration increased blood pressure from 151/ $106 \mathrm{mmHg}$ to $232 / 143 \mathrm{mmHg}$ at $30 \mathrm{~min}$. Blood pressure also rose from 170/110 $\mathrm{mmHg}$ to $220 / 140 \mathrm{mmHg}$ at $30 \mathrm{~min}$ with the treatment of $\mathrm{DPD}$. The patient had an extremely high value of $\mathrm{NA}(31,000 \mathrm{pg} / \mathrm{ml})$, whereas normal of Adr (100 pg/ $\mathrm{ml})$. The DPD treatment increased NA to the value of more than $40,000 \mathrm{pg} / \mathrm{ml}$ both at 15 and $30 \mathrm{~min}$, while a slight increment was observed in Adr which were $432 \mathrm{pg} / \mathrm{ml}$ and $181 \mathrm{pg} / \mathrm{ml}$ at $15 \mathrm{~min}$ and $30 \mathrm{~min}$, respectively.

In these two patients the treatment not only with MCP but also with DPD produced a marked rise in blood pressure owing to increased secretion of NA with or without $\mathrm{Adr}$ from the adrenal tumor. The result suggests that another dopamine antagonist, DPD, which differs in chemical structure from MCP and sulpiride, might also induce hypertensive crisis in pheochromocytoma. Accordingly, DPD as well as MCP and sulpiride should not be prescribed when pheochromocytoma is suspected.

It should be noted in the present study that only a slight increase in blood pressure was observed in the first case when he received MCP, $10 \mathrm{mg}$, at nonhypertensive stage, whereas the marked increment was shown with MCP, $5 \mathrm{mg}$ at 
hypertensive stage. Thus, it is questionalble to apply MCP to a useful provocation test for patients with intermittent hypertension in pheochromocytoma at non-hypertensive stage, although studying in large numbers of patients is needed. If the mechanisms whereby hypertensive crisis is induced by DPD are the same with those by MCP, DPD could not either be applicable to the test.

\section{References}

1) Agabiti-Rosei, E., Alicandri, C.L. \& Corea, L. (1977) Hypertensive crisis in patients with pheochromocytoma given metoclopramide. Lancet, 1, 600.

2) Agid, Y., Pollak, P., Bonnet, A.M. \& Signoret, J.L. (1979) Bromocriptine associated with a peripheral dopamine blocking agent in treatment of Parkinson's disease. Lancet, 1, 570-572.

3) Oishi, S., Shimada T. \& Sato, T. (1983) A case of an intrathoracic pheochromocytoma occurring 9 years after resection of an intraabdominal paraaortic pheochromocytoma: catecholamine secretion from the cultured pheochromocytoma tissues by metoclopramide and sulpiride. Folia endocr. jap. 59, 1608-1619. (Japanese)

4) Plouin, P.F., Menard, J. \& Corvol, P. (1976) Hypertensive crisis in patients with pheochromocytoma. Lancet, 2, 1357-1358. 